\title{
Substitution Buccal Mucosal Graft Urethroplasty for Long Segment Anterior Urethral Stricture : Our Experience in Dorsolateral Onlay Approach
}

\author{
Shiba Prasad Nandy ${ }^{{ }^{*}}$ \\ Md. Asaduzzaman ${ }^{1}$ \\ Kamal Uddin Mazumder ${ }^{1}$ \\ Sakhawat Mahamud Khan ${ }^{1}$ \\ Md. Monowar-Ul-Hoque ${ }^{1}$ \\ 'Department of Urology \\ Chittagong Medical College Hospital \\ Chattogram, Bangladesh.
}

\begin{abstract}
Background: Currently the most favorable single stage procedure for management of long segment anterior urethral stricture is dorsal onlay technique of urethroplasty. This required circumferential extensive mobilization of the urethra, which might cause ischemia of urethra in addition to chordee. To evaluate the short term outcome of dorsolateral onlay BMG (Buccal Mucosal Graft) urethroplasty by unilateral urethral mobilization for treatment of long segment anterior urethral stricture
\end{abstract}

Materials and methods: A prospective experimental study from January 2016 to December 2018 is carried out in Department of Urology, Chittagong Medical College Hospital (CMCH) Chattogram, Bangladesh. Total 32 patients of long segment anterior urethral stricture were treated by dorsolateral onlay BMG urethroplasty by unilateral urethral mobilization. Stricture $>2 \mathrm{~cm}$ were included; RGU, MCU and Uroflowmetry were the mainstay of assessment. Success was defined as maximum flow rate $>15 \mathrm{ml} / \mathrm{s}$, normal RGU and/ urethroscopy. Failure considered as presence of obstructive symptoms, Qmax $<15 \mathrm{ml} / \mathrm{s}$, stricture on RGU and any post-operative urethral intervention.

Results: Mean stricture length was $48.72 \mathrm{~mm}$ (Range: $30-77 \mathrm{~mm}$ ) and mean follow up time was 22.4months (Range: 12-40 months). Three patients were found to develop stricture at proximal anastomotic site during follow up and required optical internal urethrotomy and considered as failure. 01 patients developed Surgical Site Infection (SSI) which resolved after regular dressing. Success rate was $90.7 \%$

Conclusion: Dorsolateral onlay BMG urethroplasty by unilateral mobilization is feasible, safe and easily adoptable for long segment anterior urethral stricture with good short term outcome.

Key words: BMG; Optical internal urethrotomy; SSI; Urethral stricture.

\section{INTRODUCTION}

Urethral stricture is a common disease encountered by urologist ${ }^{1}$. The surgical treatment of urethral strictures varies according to etiology, location, length, density of lesion and fibrosis involving the surrounding tissue ${ }^{2,3}$. There are different modalities for short segment strictures including simple dilatation, visual internal urethrotomy, scar excision and end to end anastomosis, while management of long segmentis technically challenging and a complex one. The conventional approach for management of long segment anterior urethral stricture is a two stage Johanson procedure along with the use of free graft in needed ${ }^{4,5}$. On the other hand, for long segment stricture dorsal, ventral or lateral onlay or inlay graft technique may be employed as single stage procedure recently ${ }^{6}$. Out of these, dorsal onlay urethroplasty is the most favored policy now ${ }^{7}$. 
Urethral substitution has long been accomplished by using genital skin flap, graft of genital or extragenital tissue ${ }^{8}$. Now a days, buccal mucosa has emerged the best among the other grafts with promising early results ${ }^{9}$. The use of oral mucosa was first described in 1941 by Humby. Buccal mucosa is tough, moist, resilient for thick epithelium, rich in sub dermal lymphatic, easy to harvest, easy to handle, resistant to some genital skin diseases, rapid healing and minimum donor site morbidity. Thus it likely to become new gold standard for urethral substitution ${ }^{10}$.

Recently in different study it has been recommended that dorsolateral onlay BMG urethroplasty by unilateral urethral mobilization which preserved vascular supply in one side and minimize ischemia with less chance of development of chordee. ${ }^{11}$ Total procedure is carried out through perineal incision except meatotomy. Avoiding penile incision minimizes chance of wound infection and fistula formation. ${ }^{12}$ Preservation of unilateral vascular supply of urethra perfects the surgical technique of reconstruction by minimal invasive approach. These recent proposals of unilateral mobilization of urethra sparing central tendon of perineum and dorsolateral placement of BMG in order to preserve blood supply of urethra and neuro vascular integrity of bulbospongiosus muscle ${ }^{13}$.

We present our experiences in single stage substitution BMG urethroplasty with dorsolateral onlay technique for long segment anterior urethral stricture through a perineal incision. The objectives were to evaluate the clinical outcome and complications of the performed procedure.

\section{METHODS AND MATERIALS}

This prospective study was conducted in the Department of Urology, CMCH, Chattogram, Bangladesh from January 2016 to December 2018 having 32 cases of BMG urethroplasty. Patients with anterior and recurrent urethral stricture $>2 \mathrm{~cm}$ were included and patients with severe co-morbidity and soft stricture $<2 \mathrm{~cm}$ were excluded from the study. Age limit of the study was 27-46 years.

Preoperative evaluation included history, brief physical examination, urinalysis, USG of KUB with PVR, RGU and MCU, Uroflowmetry.

An intraoperative urethroscopy was performed to evaluated the stricture site caliber and normal part. We performed the dorsolateral onlay procedure only if the urethra was at least $6 \mathrm{fr}$ diameter. Urethroplasty was performed by a midline perineal approach with patient in high lithotomy position.

The penis was everted through the perineal wound. Urethra was mobilized unilaterally from the midline on ventral aspect to beyond the midline on dorsal aspect. Fascia and vascular attachment on another side remain intact. Maximum distal and proximal limit of dissection were meatus and bulbomembranous junction respectively. Urethrotomy was made in the midline dorsally. BMG of required length and breadth were taken from one or both cheek. Proximally, graft was sutured to the open urethra by a few interrupted sutures at the apex and margin. Then, one edge of the graft was sutured with the medial urethral margin and fixed to the corpora. Continuous suturing with 4/0 vicryl was done until the distal apex. Quilting suturing was done to keep the graft opposed to the tunica and to prevent buckling. A 14fr Foley catheter was kept. Another margin of the graft was sutured with the lateral margin of urethra and tunica of corpora. Graft was placed upstretched to prevent chordee. Bulbospongiosus muscle was approximated in the midline.

Catheter was kept in situ for 3 weeks. Patient was ambulated on $1^{\text {st }}$ POD and was discharged from the hospital on 3 to 5 POD. All patients were given per-operative broad spectrum parenteral antibioticsfollowed by oral preparation according to previous urine $\mathrm{C} / \mathrm{S}$, till removal of catheter. All patients were follow up at 1,3,6,9 and 12 months postoperatively. At every visit patients were assessed bysymptoms, urine R/M/E and C/S, USG with PVR and Uroflowmetry.

The results were classified into the following outcomes. Success was defined as Qmax $>15 \mathrm{ml} / \mathrm{s}$, normal RGU and/or urethroscopy. Failure was defined as the presence of obstructive urinary tract symptoms, Qmax $<15 \mathrm{ml} / \mathrm{s}$, stricture diagnosed on RGU/urethroscopy and need of any postoperative urethral intervention.

Data were processed and analyzed using SPSS software and the statistical tests used were Chi-square test, Student's t-test. The level of significance was set at 0.05 and $p<0.05$ was considered significant.

\section{RESULTS}

Mean age of the patients was 38.25 years (Range 27- 46 years). Mean stricture length was $48.72 \mathrm{~mm}$, where most of the strictures were present in penobulbar part (43.8\%). Rest were bulbar $25 \%$ and penile $31.2 \%$. Most common presentation of the patients was poor flow. Etiology of the stricture was inflammatory (25\%), Balanitis Xerotica Obliterans (BXO) $(24.9 \%)$ traumatic $(15.6 \%)$ and both idiopathic and iatrogenic were in same number (18.7\%). Mean preoperative Qmax was $6.75 \mathrm{ml} / \mathrm{s}$ where postoperative Qmax was $23.47 \mathrm{ml} / \mathrm{s}$ which was statistically significant $(\mathrm{p}<0.001)$. Preoperative USG showed average PVR was $132.45 \mathrm{ml}$ but postoperatively majority of the patients $(87.5 \%)$ did not show any significant PVR. Operative time was 1.5 to 2.5 hours and mean follow up time was 22.4 months (Range: 12 to 40 months). During follow up 02 patients (6.3\%) developed fistula, urinary dribbling in 01 patient $(3.1 \%)$, wound infection and re-stricture in 03 (9.4\%) each. Finally, 29 patients were satisfied with surgery and their Qmax $>15 \mathrm{ml} / \mathrm{s}$. Three patients developed stricture at graft site and voided with poor stream. We managed them with OIU, but 01 patients had persistent narrowing which was managed by redo BMG Urethroplasty. No patients developed postoperative chordee or diverticulum in this study. 
Table : Preoperative evaluation

$\begin{array}{lllll}\begin{array}{l}\text { Age } \\ \text { (In year) }\end{array} & \begin{array}{l}\text { Length of stricture } \\ \text { (In mm) }\end{array} & \begin{array}{l}\text { Site of stricture } \\ \text { (n) }\end{array} & \begin{array}{l}\text { Qmax } \\ (\mathrm{ml} / \mathrm{s})\end{array} & \text { PVR (ml) } \\ \text { R: } 27-46 & \text { R: } 30-78 & \begin{array}{c}\text { Bulbar: } 8 \\ \text { Penobulbar: } 14\end{array} & \text { R: } 3-11 & \text { R: } 12-20 \\ \text { M: } 38.25 & \text { M: } 48.72 & \text { Penile: } 10 & \text { M: } 6.75 & \text { M: } 132.45 \\ & & & \end{array}$

Table II : Postoperative outcome

\begin{tabular}{llll}
$\begin{array}{l}\text { Time } \\
\text { (Postoperative) }\end{array}$ & $\begin{array}{l}\text { Preoperative Qmax } \\
\text { Mean } \pm \text { SD }\end{array}$ & $\begin{array}{l}\text { Postoperative Qmax } \\
\text { Mean } \pm \text { SD }\end{array}$ & p value \\
01 month & $6.75 \pm 1.85$ & $28.75 \pm 3.02$ & 0.001 \\
03 month & $6.75 \pm 1.85$ & $30.06 \pm 3.24$ & 0.001 \\
06 month & $6.75 \pm 1.85$ & $29.72 \pm 2.97$ & 0.001 \\
09 month & $6.75 \pm 1.85$ & $29.45 \pm 2.78$ & 0.001 \\
12 month & $6.75 \pm 1.85$ & $29.02 \pm 2.54$ & 0.001 \\
\hline
\end{tabular}

Table III : Postoperative complication

\section{Complications}

No of patients $(\%)$

Fistula

Recurrent stricture

$2(6.3 \%)$

Recurrent urethritis

$3(9.4 \%)$

Wound infection

$3(9.4 \%)$

Post micturition dribbling

$1(3.1 \%)$

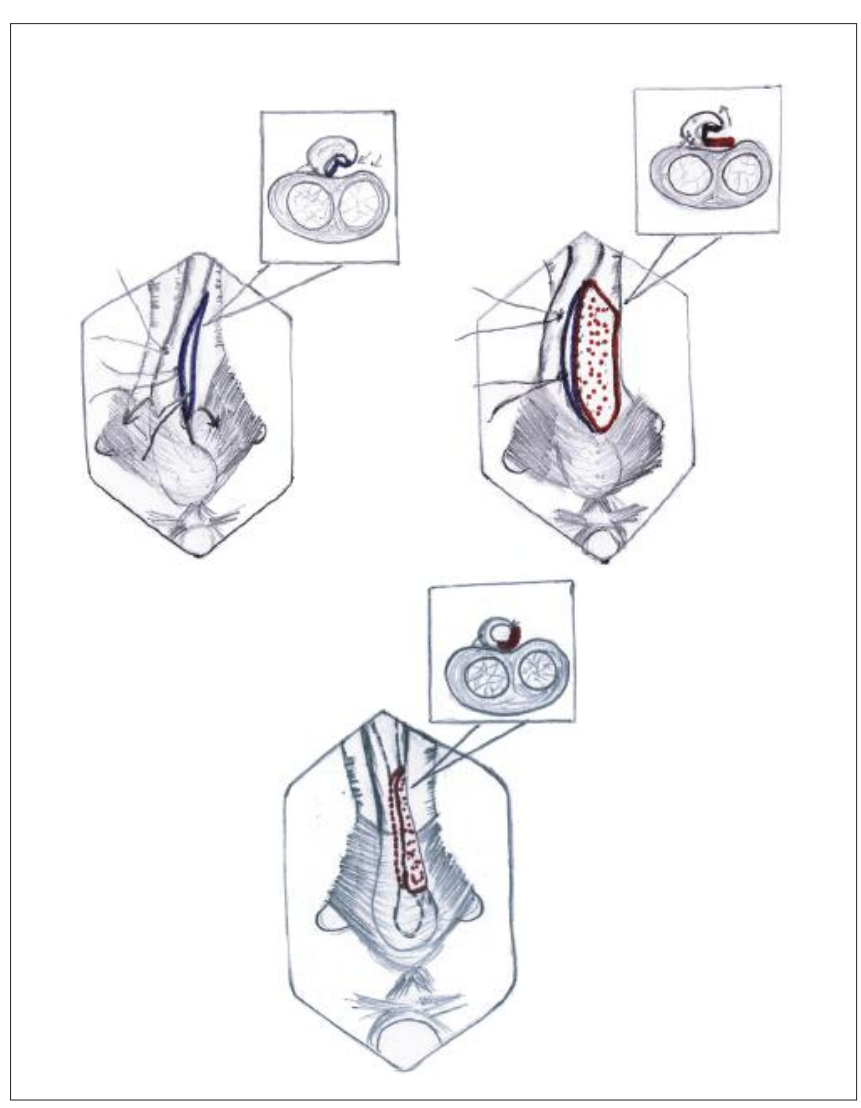

Figure 1 : Procedure of dorsolateral onlay BMG Urethroplasty

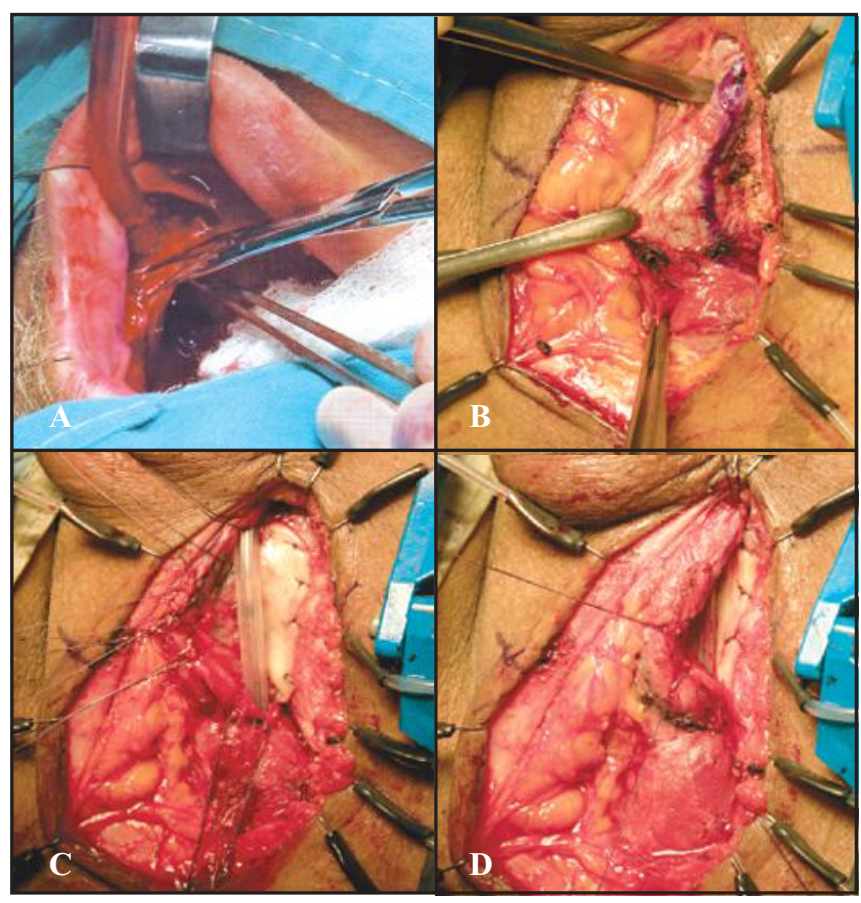

Figure 2 : Dorsolateral Onlay BMG Urethroplasty: A) Harvesting of buccalmucosa B) Unilateral dissection at recipient site C) Graft placement D) Closure of recipient site Source: Personal Series

\section{DISCUSSION}

In case of most popular dorsal onlay technique, conventional circumferential dissection of the whole anterior urethra risks the vascularity of the urethra, which may be more important if meatus is involved with disease. Barbagli procedure for dorsal onlay graft placement shows $66 \%$ success rate in long term ${ }^{11}$. Ventral inlay technique by Asopa is another option for anterior urethral stricture which preserves lateral vascularity of urethra but technically difficult one. However, Barbagli also described, in bulbar urethral stricture, dorsal, ventral or lateral onlay placement of the graft provide similar results ${ }^{14}$.

To maintain one sided urethral vascularity by using the graft in dorsolateral onlay fashion, we adopted the Kulkarni's technique. Technically it is easy and preserves one sided bulbar artery in addition to maintain the native lateral vascularity at meatus and distal urethra. In this procedure we did not find any postoperative chordee case. Urethra is not completely mobilized off the corpora, hence graft sizing is more accurate which prevent chordee. We cannot comment on postoperative sexual and ejaculatory function as minimum information could not collect by valid questionnaire due to lack of knowledge of our maximum patients. But the muscle and nerve sparing dorsolateral onlay procedure suggested for better ejaculatory function and to avoid postoperative dribbling ${ }^{11}$.

Regarding postoperative patients compliance, 28 patients $(87.5 \%)$ were satisfied with surgery upto 22.4 months mean 
follow up. In their study, they were reported 94\%, 85\%, 96\%, $76 \%$ and $94.2 \%$ success rate respectively through this approach with a mean follow up of 19, 22.7, 18, 18 and 12 months ${ }^{11,12,14,15}$. Kulkarni et al shows in the study of 24 patients with mean follow up of 22 months, 92\% successful outcome where $02(8 \%)$ were failed ${ }^{13}$. In our study, mean pre and postoperative Qmax were $6.75 \mathrm{ml} / \mathrm{s}$ and $23.47 \mathrm{ml} / \mathrm{s}$ whereas Prabha et al and Mowladad et al showed $6.5 \mathrm{ml} / \mathrm{s}$ and $24 \mathrm{ml} / \mathrm{s}$, $6.08 \mathrm{ml} / \mathrm{s}$ and $29.04 \mathrm{ml} / \mathrm{s}$ respectively in their studys ${ }^{12,14}$. Prabha et al, Tapas Majhi, Prakasa et al, reported that most common complication was wound infection $(10 \%, 10 \%$, $11.4 \%)$ which is also similar to us $(9.4 \%)^{4,12,15}$.

\section{CONCLUSION}

Preservation of one sided vascular supply of urethra and its entire muscular and neurogenic support significantly towards perfecting the surgical technique of reconstruction in long segment anterior urethral stricture. In this study, we found it as a minimally invasive, safe and successful procedure with agood outcome.

\section{DISCLOSURE}

All the authors declared no competing interest.

\section{REFERENCES}

1. Palminteri E, LazzeriM,Turini D, Barbagli G. New 2-stage buccal mucosal graft urethroplasty. J Urol. 2002;167:130-132

2. Peterson CA and Webster GD Management of urethral stricture disease: Development options for surgical intervention. BJU Int. 2004;94:971-976.

3. Fanton AS, Morey AF, Aviles R, Garcia CR. Anterior urethral stricture: Etiology and characteristics. Urology. 2005; 65(6):1055-1058.

4. Dr. Tapas Kumar Majhi. Dorsolateral Onlay BMG urethroplasty in long segment anterior urethral stricture : Our experience. IOSR-JDMS. 2017;16(9):87-92.

5. Schreiter F. Two stage urethroplasty. UrologeA. 1998; 37: 42-50.

6. Barbagli G, Palminteri E, Guazzoni G, Montorsi F, Turini D, Lazzeri M. Bulbar urethroplasty using buccal mucosa grafts placed on the ventral, dorsal or lateral surface of the urethra: Are results affected by the surgical technique? J Urol. 2005;174:955-957.

7. Patterson JM, Chapple CR. Surgical technique in substitution urethroplasty using buccal mucosa for the treatment of anterior urethral stricture. EurUrol. 2008; 503: 1162-1166.

8. Pahwa M, Gupta S, Pahwa M, Jain BDK and Gupta M. A comparative study of dorsal buccal mucosal graft substitution urethroplasty by dorsal urethrotomy approach versus ventral sagittal urethrotomy approach. Article ID-124836. 2013;1-5.

9. Caldamone AA, Edstrom LE, Koyle MAS, Patterson JM, Inman RD, MacNeil S. Buccal mucosal graft for urethral reconstruction. Urology. 1998;51:15-19.

10. Bhargava S and Chapple CR. Buccal mucosal graft urethroplasty: Is it the new gold standard? BJU Int. 2004;93:1191-1193.

11. Singh BP, Pathak HR and Andankar MG. Dorsolateral onlay urethroplasty for anterior urethral strictures by a unilateral urethral mobilization approach. Indian J Urol. 2009;25:211-212.

12. Prabha V, Shishir D, Vernekar R, Hiremath M. Single stage dorsolateral onlay buccal mucosal urethroplasty for long anterior urethral strictures using perineal route. BRAZ J Urol. 2016;42:564-570.

13. Kulkarni SB, Barbagli G and Salvatore S. One sided anterior urethroplasty: A new dorsal onlay graft technique. BJU International. 2009;104:1150-1155.

14. Mowladad CATM, Rahaman KM, Baktiar A, Rafiqul H, Shofiqur H and Faruquzzaman. Post-surgical outcomes of dorsolateral onlay urethroplasty. AKMMC J. 2016;7(2):16-19

15. Prakasa RB, Prabhakar RM, Sridhar P. Dorsolateral onlay BMG urethroplasty in the management of inflammatory stricture urethra: A prospective clinical study. GJRA. 2016;5:30-32

16. Habib AKMK, Alam AKMK, Amanullah ATM, Rahaman H, Hossain AKMS, Salam MA, Kibria SAMG. Dorsolateral onlay urethroplasty for long segment anterior urethral stricture: Outcome of a new technique, BMRC. 2011;37:78-82. 